\title{
Extracellular synthesis of silver nanoparticles using entomopathogenic fungus: characterization and antibacterial potential
}

\author{
Shruti Tyagi ${ }^{1} \cdot$ Pankaj Kumar Tyagi $^{2} \cdot$ Deepak Gola $^{2} \cdot$ Nitin Chauhan $^{3} \cdot$ Randhir K. Bharti $^{4}$
}

Received: 24 September 2019 / Accepted: 29 October 2019 / Published online: 5 November 2019

(c) Springer Nature Switzerland AG 2019

\begin{abstract}
Present study involves the simple, rapid, non-toxic and in vitro method of extracellular silver nanoparticles synthesis using Entomopathogenic fungus (Beauveria bassiana). The development of silver nanoparticle in fungal supernatant was confirmed by the absorbance peak at $450 \mathrm{~nm}$ in UV-Vis spectrophotometer. Further, presence of AgNPs and its crystal lattice was confirmed by EDS and XRD, respectively. TEM micrograph confirmed the presence of differently shaped (triangular, circular, hexagonal) nanoparticles with size ranging from 10 to $50 \mathrm{~nm}$. Variable shape and size of fungal assisted AgNps was also confirmed in SEM study. The optimal pH and temperature for biosynthesis of nanoparticles was found to be 6.0 and $25^{\circ} \mathrm{C}$, respectively. The continuous effects of AgNPs against Escherichia coli, Pseudomonas aeruginosa and Staphylococcus aureus in time dependent manner was confirmed in growth kinetic studies. During $36 \mathrm{~h}$ of growth study, maximum reduction in $O_{.} D_{560}$ was found in $E$. coli (67.2\%) followed by $P$. aeruginosa (63.3\%) and S. aureus $(56.8 \%)$ at $30^{\circ} \mathrm{C}$. The MIC values of fungal assisted AgNPs against E. coli, P. aeruginosa and S. aureus was found to be 2.5, 3 and $4.5 \mathrm{ppm}$, respectively. The MIC values of Ciprofloxacin was observed to be $0.5,0.5$ and $0.7 \mathrm{ppm}$, whereas MICs of AgNPs + Ciprofloxacin showed $0.4,0.4,0.5$ ppm against $E$. coli, P. aeruginosa and S. aureus, respectively, clearly highlighting the synergistic effect of AgNPs in combination with Ciprofloxacin. In the view of challenges for developing antimicrobial nanoparticles of variable shape and size by various other methods, tuning nanoparticles synthesis via fungi can be a wonderful approach to resolve existing hurdles.
\end{abstract}

Keywords Silver nanoparticles · Entomopathogenic fungi · Antimicrobial · Antibiotic

\section{Introduction}

The term "nano" is derived from a Greek word which means "dwarf" [1, 2]. Synthesis of nanoparticles has gained attention due to their applications in multiple fields such as antifungal agents, antibacterial agents, biosensor, bioremediation, anticancer, drug delivery, etc. [3-10]. In addition to this, unique properties of nanoparticles such as size, shape, surface to volume ratio, high catalytic activity, etc. make them a unique candidate for multiple applications described above. The synthesis of nanoparticles via biological means has proved to be the better mode as compared to chemical and physical methods [1]. Chemical methods involve toxic chemicals and may generate hazardous or toxic by-product during synthesis, while physical methods have low efficiency and involves high consumption of energy to maintain optimal pressure and temperature during the synthesis

$\triangle$ Deepak Gola, deepakgola@gmail.com $\mid{ }^{1}$ Meerut Institute of Engineering and Technology, Meerut, Uttar Pradesh, India. ${ }^{2}$ Noida Institute of Engineering and Technology, Greater Noida, Uttar Pradesh, India. ${ }^{3}$ Department of Microbiology, Shaheed Rajguru College of Applied Sciences for Women, University of Delhi, New Delhi, Delhi, India. ${ }^{4}$ University School of Environmental Management, Guru Gobind Singh Indraprastha University, Dwarka, Delhi, India. 
process $[11,12]$. On the other hand, biological methods for the synthesis of silver nanoparticles provides many advantages i.e., environmental friendly, non-toxic and easy to scale up for large-scale synthesis [13-15]. Researcher across the world utilized biological entities such as plant (leafs, flower, seeds), bacteria, algae and fungi for the production of different type of metallic nanoparticles such as gold, silver, cadmium, iron, etc. and studied their applications in the field of medical, bioremediation, drug delivery etc. [16-19].

Among other metal nanoparticles, synthesis of silver nanoparticles (AgNPs) via biological mean gain wide acceleration due to their profound applications in medical application, textile dye removal, wastewater treatment, biological sensors etc. [16, 20-22]. Synthesis of AgNPs via fungi gain more attention because they produce large amount of biomass in a short period of time under lab conditions and produce large amount of extracellular protein that help in synthesis of nanoparticles [23, 24]. Dhanaraj et al. [17] observed the AgNPs synthesis potential of fungi Aspergillus niger and observed significant anti-bacterial properties of AgNPs against Staphylococcus aureus, Klebsiella pneumonia, Escherichia coli, and Salmonella typhi. In another study, Verma et al. [25] investigated the antimicrobial potential of AgNPs synthesized through Aspergillu sclavatus against Candida albicans, Pseudomonas fluorescens and Escherichia coli. Results clearly indicated anti-microbial activity with average minimum inhibitory concentration of $5.83 \mu \mathrm{g} \mathrm{mL}^{-1}$ against above microbial pathogens. However, the literature discussing about synthesis of AgNPs using entomopathogenic fungus and antimicrobial potential of synthesized nanoparticles is lacking $[26,27]$. Most of the studies investigates larvicidal and insecticidal properties of these fungi [28]. Synthesis of AgNPs using entomopathogenic fungus provides additional advantages as they are non-pathogenic and insecticidal in nature. Earlier reports have highlighted the insecticidal potential of $B$. basssiana (entomopathogenic fungi) AgNPs. As per our findings, only one report has studied the antimicrobial efficacy of B. bassiana AgNPs against Staphylococcus aureus and Escherichia coli using well diffusion assay [29].

The present study investigated the extracellular AgNPs synthesis using Beauveria bassiana (entomopathogenic fungus) along with their antimicrobial potential. The antimicrobial activity of silver nanoparticles was compared with the antibiotic and AgNPs-antibiotic combination. The present report is the first investigation on the kinetic study of B. bassiana synthesized AgNPs against gram positive and negative bacteria at different time intervals with additional studies on AgNPs and antibiotic combination. Further, AgNPs were characterised via Transmission electron microscopy (TEM) equipped Energy dispersive spectrometer (EDS), Scanning electron microscopy (SEM), $\mathrm{X}$-ray diffraction (XRD) and zeta potential.

\section{Materials and methods}

\subsection{Micro-organisms and growth conditions}

In the present work, Beauveria bassiana was obtained from Institute of Microbial Technology (Chandigarh, India). The strain was stored at $4{ }^{\circ} \mathrm{C}$ on potato dextrose agar slant. Prior to experiments, culture was reactivated on potato dextrose agar at $25^{\circ} \mathrm{C}$ for $72 \mathrm{~h}$ [29]. Culture of Escherichia coli, Pseudomonas aeruginosa and Staphylococcus aureus stored at $4{ }^{\circ} \mathrm{C}$ on nutrient agar slant. Prior to experiments, fresh culture of each bacterial strain was prepared on nutrient broth at $37^{\circ} \mathrm{C}$.

\subsection{Extracellular synthesis of silver nanoparticles}

Spores from freshly prepared slants of $B$. bassiana was inoculated to a liquid composite media $100 \mathrm{~mL}\left(\mathrm{NH}_{4} \mathrm{NO}_{3}\right.$, $0.5 \mathrm{~g} \mathrm{~L}^{-1} ; \mathrm{MgSO}_{4} \cdot 7 \mathrm{H}_{2} \mathrm{O}, 0.1 \mathrm{~g} \mathrm{~L}^{-1} ; \mathrm{K}_{2} \mathrm{HPO}_{4}, 0.5 \mathrm{~g} \mathrm{~L}^{-1} ; \mathrm{NaCl}$, $1 \mathrm{~g} \mathrm{~L}^{-1}$; Glucose, $10 \mathrm{~g} \mathrm{~L}^{-1}$; Yeast extract, $2.5 \mathrm{~g} \mathrm{~L}^{-1}$ ) in an Erlenmeyer flask ( $250 \mathrm{~mL}$ ) [31]. The flask was incubated at $30^{\circ} \mathrm{C}$ at $150 \mathrm{rpm}$ for $72 \mathrm{~h}$ (Orbitek, India). The biomass was harvested after $72 \mathrm{~h}$ of growth by using Whatman No. 1 filter paper. After harvesting the biomass, extensive washing with distilled water was performed to remove any media components from the biomass. Ten gram of above wet biomass was taken into an Erlenmeyer flask $(250 \mathrm{~mL})$ containing $100 \mathrm{~mL}$ distilled water and flask was incubated for $48 \mathrm{~h}$ at $25^{\circ} \mathrm{C}$ and $150 \mathrm{rpm}$. After $48 \mathrm{~h}$, the filtrate from the flask was obtained by passing flask content through Whatman No. 1 filter paper. The filtrate was mixed with $1 \mathrm{mM}$ silver nitrate $\left(\mathrm{AgNO}_{3}\right)$ in the ratio of $1: 9(\mathrm{v} / \mathrm{v})$ to obtain the desired reaction mixture. Afterward, reaction mixture was incubated at $25^{\circ} \mathrm{C}$ in dark for $30 \mathrm{~min}$ at $100 \mathrm{rpm}$. Control (without $\mathrm{AgNO}_{3}$ ) was incubated under the same conditions.

Colour change of the above reaction mixture was the first indicator of nanoparticle synthesis. The reaction mixture with silver nanoparticles (AgNPs) turned brown in colour and it was stored under ambient dark conditions for further analysis and experiments.

\subsection{Optimization of physio-chemical parameters for AgNPs synthesis}

Effect of temperature and $\mathrm{pH}$ on the synthesis of AgNPs was investigated by varying the the temperature $\left(15-40^{\circ} \mathrm{C}\right)$ and $\mathrm{pH}(3-9)$. To obtained the desired $\mathrm{pH}$ value of fungal extract $\mathrm{NaOH}$ and $\mathrm{HCl}$ was used prior to the 
addition of silver nitrate. Sample of $1 \mathrm{~mL}$ was withdrawn after $30 \mathrm{~min}$ and the absorbance was measured at $450 \mathrm{~nm}$.

\subsection{Characterization of AgNPs}

\subsubsection{Ultraviolent-visible spectroscopy}

The Ultraviolet-visible spectroscopy analysis of freshly prepared AgNPs was obtained using the Agilent spectrophotometer with water as control. Samples from reaction mixture for UV-Vis spectra were withdrawn at a regular interval of $10 \mathrm{~min}$ for overall reaction time of $30 \mathrm{~min}$. The spectra were recorded in a wavelength ranging from 300 to $1000 \mathrm{~nm}$ at a resolution of $0.5 \mathrm{~nm}$.

\subsubsection{Zeta potential-dynamic light scattering}

Zeta potential was used to determine the charge that exists between the AgNPs using Nano ZS90 Zeta sizer (Malvern Instruments) equipped with $\mathrm{He}-\mathrm{Ne}$ laser (633 nm, $5 \mathrm{Mw})$.

\subsubsection{Transmission electron microscopy and energy dispersive spectrometer}

To determine the size and the shape of the AgNPs, Transmission electron microscopy was performed. The sample for TEM was prepared by dropping the solution of AgNPs on the carbon side of carbon-copper grid. After drying for $30 \mathrm{~min}$, grid was placed on the sample holder and micrographs were obtained for size and shape analysis. For TEM images, sample was analysed via EOL JEM-1400. On the other hand, Energy dispersive micrograph was obtained by Bruker-ASX (Model QuanTax 200) was used.

\subsubsection{Scanning electron microscopy}

The nanoparticle sample was lyophilized and characterized further to study the morphological features using scanning electron microscopy (ZEISS EVO 50).

\subsubsection{X-ray diffraction (XRD) measurement}

XRD (X-ray diffraction) was conducted for the nanoparticles using Cuka radiation $(k=1.5406 \AA)$ via $X^{\prime}$ Pert PRO Philips Analytical-PW 3040/60. The sample was examined at $40 \mathrm{kV}$ with $30 \mathrm{~mA}$ at a $2 \mathrm{~h}$ angle pattern and was scanned in the region of $25^{\circ}-80^{\circ}$. The micro-graph obtained after scanning was compared with the Joint committee on Power Diffraction Standards Library to establish the crystalline structure of nanoparticles.

\subsubsection{Antimicrobial activity of AgNPs and antibiotic}

Three different species of bacteria (Escherichia coli, Pseudomonas aeruginosa and Staphylococcus aureus) were tested for their susceptibility to the antimicrobial properties of fungal derived AgNPs in term of growth kinetic and Minimum inhibitory concentration (MIC). Effect of AgNPs on growth kinetic of bacterial strain was evaluated in $100 \mathrm{~mL}$ sterilized nutrient broth containing $1 \mathrm{ppm}$ of AgNPs and inoculated with one $\mathrm{mL}$ bacterial strain $\left(10^{6} \mathrm{CFU} / \mathrm{mL}\right)$. The media was incubated at $30^{\circ} \mathrm{C}$ at $150 \mathrm{rpm}$. Control without AgNPs was incubated under the same conditions. The flask content $(0.2 \mathrm{~mL})$ was withdrawn at a regular interval of $2 \mathrm{~h}$ for $36 \mathrm{~h}$ and optical density of the sample was measured at $560 \mathrm{~nm}$ to obtained growth curve. To determine the minimum inhibitory concentrations (MICs) for all three bacteria against AgNPs, antibiotic (Ciprofloxacin) and AgNPs-Antibiotic combination, nutrient broth was added with different concentration of AgNPs (0.5-10 ppm) and antibiotic (0.5-10 ppm), followed by bacterial inoculation. To determine the combined effects AgNPs-Ciprofloxacin different concentration of AgNPs and antibiotic ranging from 0.5 to $10 \mathrm{ppm}$ was used in ratio of 1:1. All the experiment was performed on $96-$-well titre plate which was incubated at $30^{\circ} \mathrm{C}$ after inoculation. The plate was evaluated visually for biofilm formation after $36 \mathrm{~h}$. Minimum inhibitory concentration was expressed as the lowest AgNPs concentration at which no visible growth was observed.

\section{Results and discussion}

\subsection{Extracellular synthesis of sliver nanoparticles}

When filtrate was mixed with $\mathrm{AgNO}_{3}$ solution $(1 \mathrm{mM})$, the colour of the reaction mixture turned from white to dark brown. No change in colour was observed in control flasks containing only filtrate and the other containing milli-Q water $(9 \mathrm{~mL})$ and $\mathrm{AgNO}_{3}(1 \mathrm{mM})$. Spectral analysis was done at a regular interval for $10 \mathrm{~min}$ and results are illustrated in Fig. 1. The reduction of $\mathrm{Ag}^{+1}$ to $\mathrm{Ag}^{0}$ in the reaction mixture cause colour change in reaction mixture. The maximum absorbance at $450 \mathrm{~nm}$ was observed in UV spectra analysis which is characteristic surface plasmon resonance peak of fungus assisted AgNps. As shown in Fig. 1, a clear hike in UV-vis peak with time at a wavelength of $450 \mathrm{~nm}$ indicates the continuous production of the AgNPs. It was also observed that the peak becomes narrow after $30 \mathrm{~min}$ in comparison to 10 min reading, highlighting the formation of monodispersed AgNps formation. 


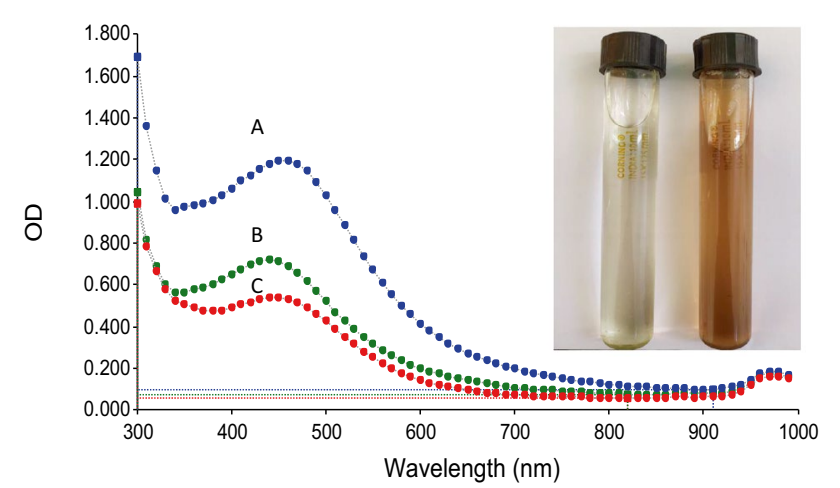

Fig. 1 UV-visible absorption spectrum of AgNPs biosynthesized by the reduction of $\mathrm{AgNO}_{3}$ solution with the fungal filtrate of $B$. Bassiana with different time intervals (a: $30 \mathrm{~min} ; \mathrm{b}: 20 \mathrm{~min}$ and c: $10 \mathrm{~min}$ )

\subsection{Characterization of AgNPs}

Figure 2 represent the TEM micrographs for the AgNPs synthesized from the fungal filtrate. Different shapes of the AgNPs such as triangular, circular, hexagonal etc. with size ranging from 10 to $50 \mathrm{~nm}$ were observed in the TEM micrograph. The size and the shape of the nanoparticle can be further optimized by varying the concentration of filtrate and $\mathrm{AgNO}_{3}$ in the reaction mixture, incubation time, $\mathrm{pH}$, aeration, salt concentration, type of method used and temperature of the reaction mixture [32]. The shape of the AgNPs significantly influences its antimicrobial properties. Pal et al. [33] investigated the effects of differently shaped AgNPs against gram negative Escherichia coli. It was concluded that triangular shaped AgNPs were more effective as compared to circular and rod shape nanoparticles [33]. In another study [34] similar high antimicrobial activity against Escherichia coli, was observed with triangular AgNPs (chemically synthesised) as compared to spherical AgNPs. Further, elemental analysis of AgNPs was confirmed by Energy dispersive spectrometer (EDS) micrograph. Presence of peaks at approximately $3 \mathrm{keV}$ in Energy dispersive spectrometer micrograph confirmed the presence of AgNPs. In addition to this, significant peak of carbon and copper were also appeared in the Energy dispersive spectrometer micrograph. Moreover, morphological features of fungus assisted nanoparticles was also visualised in scanning electron micrograph which showed variable shaped and sized nanoparticles with few clump formations as shown in Fig. 3a. Further, in order to study the crystalline nature of developed nanoparticles, XRD was performed, highlighting significant peaks at (111), (200), (220), (311), (420) (Fig. 3b) confirming face centered cubic (fcc) structures of nanoparticles as per the Joint Committee on Powder Diffraction Standards (JCPDS) file no: ICDDPDF2, PA,USA, 2007.

SN Applied Sciences

a SPRINGER NATURE journal

\subsection{Zeta potential of AgNPs}

The zeta potential value of $-22 \mathrm{mV}$ with a single and sharp peak was observed for AgNPs (Fig. 4). It was observed that negative charge exits between the biologically synthesized AgNPs. The negative or positive charge of AgNPs suspension, cause repulsion of AgNPs and reduce their ability or tendency to form aggregate, proving the stability of AgNPs. The negative charge of AgNPs might be due to the polyphenolic components released by the fungus $B$. bassiana in extract used for AgNPs synthesis. Polyphenolic compounds are released as secondary metabolites by the multiple fungus during growth [31, 35]. Polyphenolic components take part in capping during AgNPs synthesis [36]. Similar negative value of $-17.19 \mathrm{mV}$ was observed for AgNPs synthesized from fungus Trichoderma harzianium [37]. In another study by Prakasham et al. [38], a negative zeta potential of $-8.5 \mathrm{mV}$ was observed for nanoparticles synthesized using Streptomyces albidoflavis.

\subsection{Optimization of physio-chemical parameters for AgNPs synthesis}

It was observed that maximum synthesis of AgNPs take place at $30^{\circ} \mathrm{C}$ followed by $25^{\circ} \mathrm{C}$ and $35^{\circ} \mathrm{C}$ (Fig. 5). Further, it was examined that synthesis efficiency was reduced by $57.8 \%$ and $39.06 \%$ at $15^{\circ} \mathrm{C}$ and $40^{\circ} \mathrm{C}$, respectively. Similar reduction in synthesis efficiency at higher temperature was reported by Dhanaraj et al. [17]. It was observed that optimal $\mathrm{pH}$ for AgNPs synthesis was 6, same as the $\mathrm{pH}$ of the fungal supernatant (Fig. 5). Further, up to $66.9 \%$ reduction in biosynthesis of AgNPs was observed with acidic supernatant. The possible reason of low conversion efficiency at acidic $\mathrm{pH}$ is the slow rate of nucleation process for the formation of nano crystal leading to large nanoparticles [39].

\subsection{Antimicrobial activity of AgNPs (MIC and growth kinetic)}

Figure 6 illustrate the growth kinetic of microbes Escherichia coli (gram negative), Pseudomonas aeruginosa (gram negative) and Staphylococcus aureus (gram positive) in control (C) and in presence of AgNPs. The growth curve clearly indicates that AgNPs have inhibitory effect on the growth of each microbe investigated during the experiments. It was observed that lag phase for all three microbes increase from 3-4 $\mathrm{h}$ (in control) to 7-8 $\mathrm{h}$ (in presence of AgNPs). Maximum reduction in optical density at $560 \mathrm{~nm}$ was observed for Escherichia coli (67.2\%) followed by Pseudomonas aeruginosa (63.3\%) and Staphylococcus aureus $(56.8 \%)$, during $36 \mathrm{~h}$ of growth period at $30^{\circ} \mathrm{C}$. These finding clearly indicates that the presence of AgNPs 
Fig. 2 a TEM image shows biosynthesized AgNPs by $B$. bassiana. b Energy dispersive spectrometer (EDS) spectrum of AgNPs synthesized by $B$. bassiana
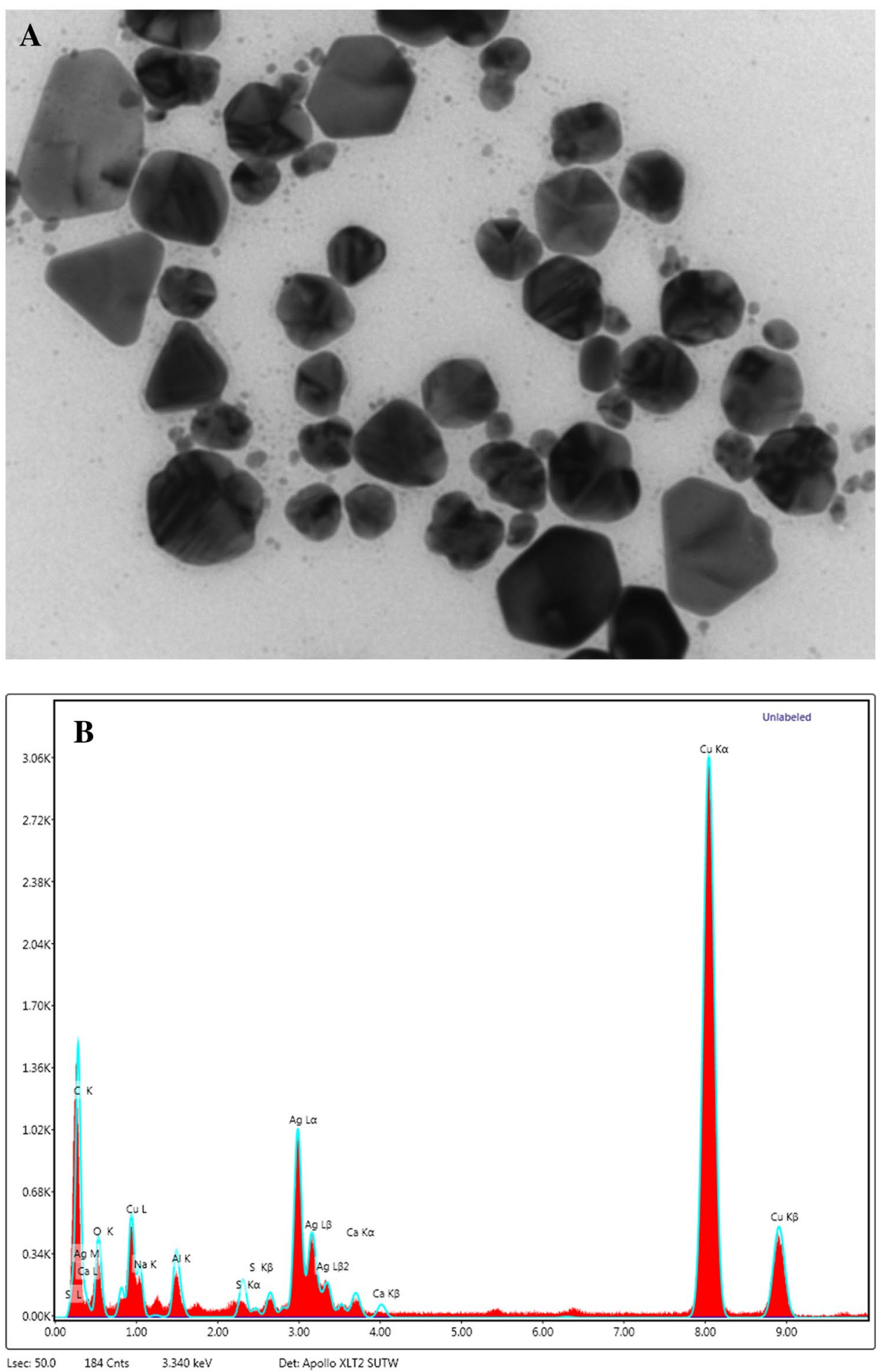

in the growth media deter the reproductive capability of microbes. Low reduction of growth in case of gram positive bacteria might be due to the presence of thick peptidoglycan layer [40]. Moreover, presence of negatively charged teichoic acids in peptidoglycan layer may result in repulsion of AgNPs, hence reducing the overall toxicity of the synthesized AgNPs against Staphylococcus aureus. A clear increase in antimicrobial potential of nanoparticles was recorded in different time scale studies, highlighting the continuous interactions of fungal assisted AgNPs with selected microbes. Chauhan et al. [41] observed various events of bacterial-AgNps interactions i.e., integration of 

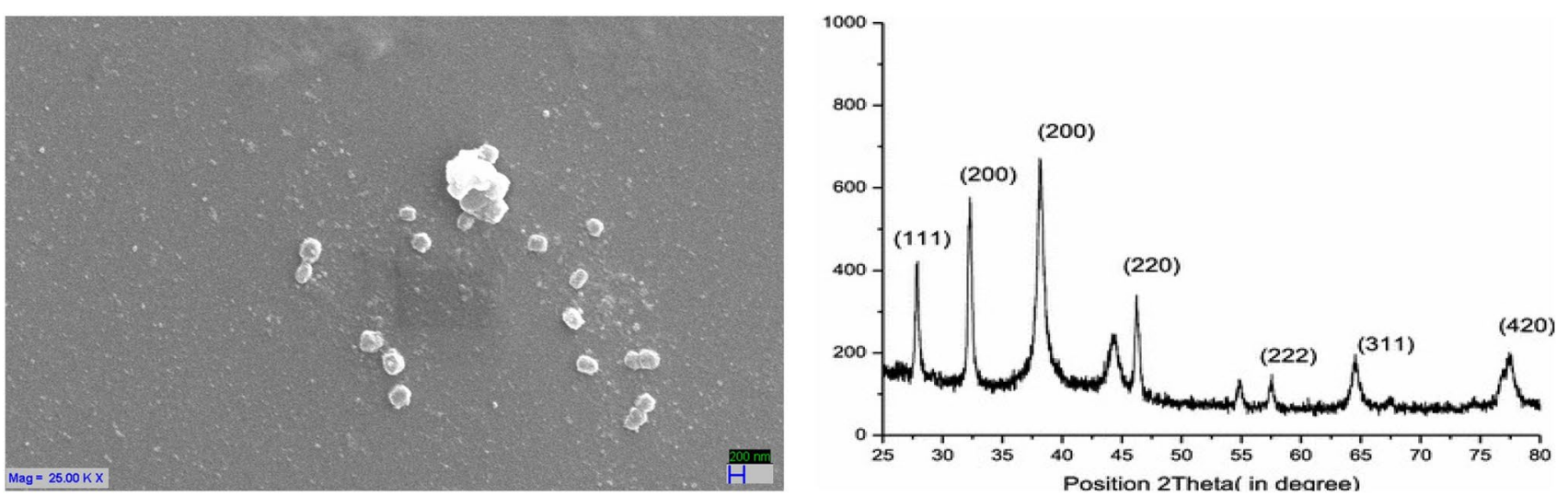

Fig. 3 a SEM image shows AgNPs produced by B. bassiana and $\mathbf{b}$ XRD micrograph shows AgNPs produced by B. bassiana

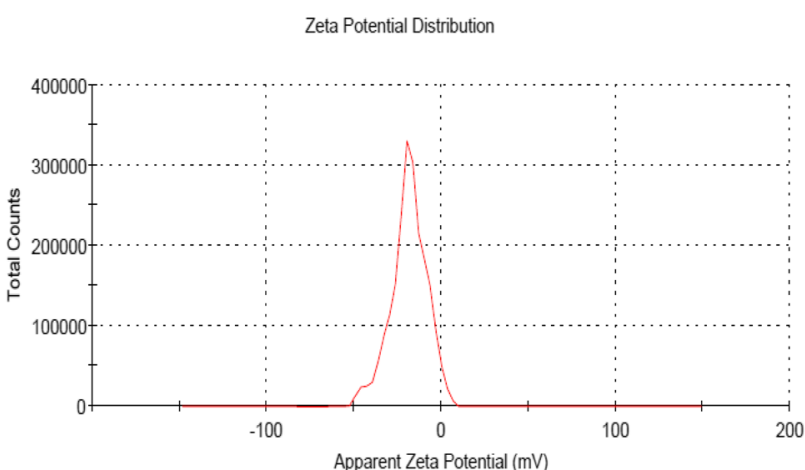

Fig. 4 Zeta potential of AgNPs produced by B. bassiana

AgNps with bacterial membrane, membrane disintegration and finally complete damage of bacterial cells.

Further, maximum MIC value for AgNPs by Staphylococcus aureus indicate the resistance provided by the peptidoglycan layer and teichoic acid [40]. The MIC value for antibiotic was found to be $0.5,0.5$ and $0.7 \mathrm{ppm}$ for Escherichia coli, Pseudomonas aeruginosa and Staphylococcus aureus, respectively (Table 1). Further, it was observed that when AgNPs was used along with antibiotic, a very low concentration was able to inhibit the total growth of each bacterium. The MIC value for AgNPs-Ciprofloxacin conjugate was found to be $0.4,0.4$ and 0.5 ppm for Escherichia coli, Pseudomonas aeruginosa and Staphylococcus aureus, respectively, showing the synergistic effect of AgNPs and antibiotic when present simultaneously. Salar et al [42], observed the similar synergistic effect of AgNPs-Streptomycin combination against Staphylococcus sp. with $18.37 \%$ increase in overall activity when present in combination as compared to antibiotic alone. Further, Smekalova et al. [43] indicate additive, synergistic and indifferent effect of AgNPs-antibiotic combination. For example, AgNPs along with amoxycillin produce additive, indifferent and synergistic effect against $S$. aureus,
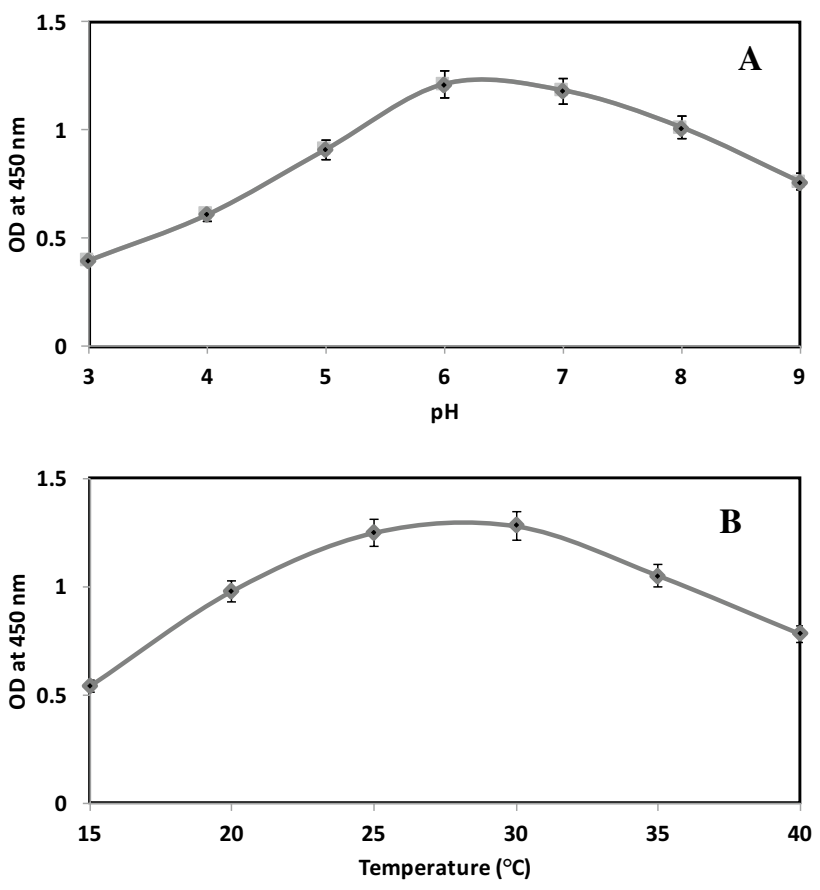

Fig. 5 a Effect of $\mathrm{pH}$ and $\mathbf{b}$ effect of temperature on the synthesis of AgNPs

E. coli and Actinobacillus pleuropneumoniae, respectively. Whereas similar AgNPs were showed synergistic effect with gentamycin against S. aureus, E. coli and Actinobacillus pleuropneumoniae. Hence, an increase in the potency of AgNPs was observed, if used in combination with antibiotics highlighting synergistic or additive effects depending on the type of antibiotic as well as type of bacterial pathogen used in the experiments. 
Fig. 6 Growth kinetic of bacterial species without and with AgNPs synthesis from $B$. bassiana at $560 \mathrm{~nm}$. (c: control and AgNPs: in presence of silver nanoparticles)

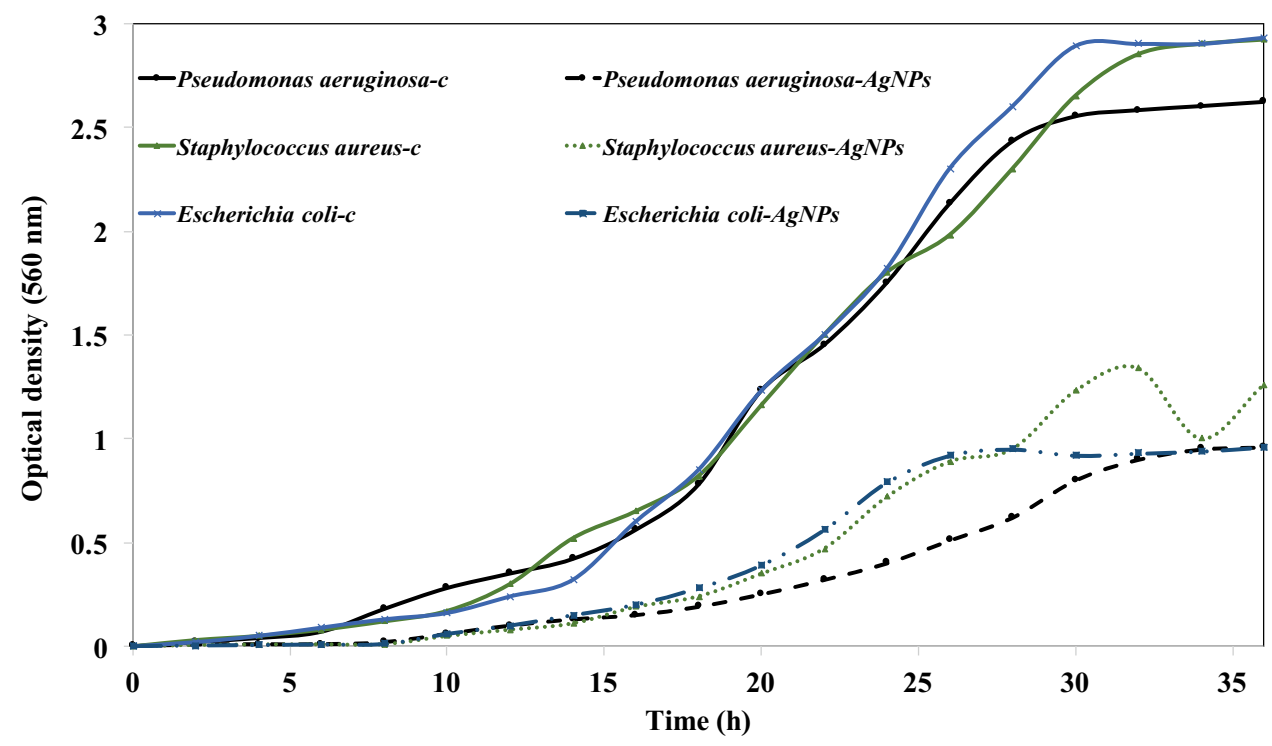

Table 1 Minimum inhibitory concentrations (MICs; ppm) of AgNPs, Ciprofloxacin and AgNPs-Ciprofloxacin

Minimum inhibitory concentration (ppm)

\begin{tabular}{llll}
\hline Bacteria & AgNPs & Ciprofloxacin & $\begin{array}{l}\text { AgNPs- } \\
\text { Ciproflox- } \\
\text { acin }\end{array}$ \\
\hline Escherichia coli & 2.5 & 0.5 & 0.4 \\
Pseudomonas aeruginosa & 3 & 0.5 & 0.4 \\
Staphylococcus aureus & 4.5 & 0.7 & 0.5 \\
\hline
\end{tabular}

\section{Conclusion}

The present study clearly demonstrated the potential of selected Entomopathogenic fungus, B. bassiana for development of extracellular silver nanoparticles (AgNPs). Various analytical tools were used for characterisation of synthesised AgNPs i.e., UV-vis spectrophotometer, Zeta-DLS, TEM, SEM, XRD etc. The techniques used for characterisation showed synthesis of AgNPs in fungal supernatant with variable shapes (triangular, spherical, hexagonal) and size range of $10-50 \mathrm{~nm}$, the synthesized nanoparticles were found to be stable under fungal solution (Zeta: $-22 \mathrm{mV}$ ). The fungal assisted AgNPs showed time dependent increase in antimicrobial efficacy against $S$. aureus, $P$. aeruginosa and $E$. Coli, moreover synergistic effect was also observed with antibiotic, Ciprofloxacin against all the bacterial strains. Further, as development of AgNPs was performed with eco-friendly approach, it can be utilized in various sectors where safety is the primary concern i.e., environment and healthcare.
Acknowledgements Authors gratefully acknowledge CST, Uttar Pradesh [Grant no: CST/8276 (young scientist scheme) and CST/1586] for funds. We are thankful to the Department of Textile Engineering (IIT Delhi) and CRF facility (IIT Delhi) for their technical support in EDS and TEM analysis. Guidance received by Prof. Anushree Malik, CRDT, IIT Delhi is acknowledgeable.

\section{Compliance with ethical standards}

Conflict of interest The authors declare that they have no conflict of interest.

\section{References}

1. Thakkar KN, Mhatre SS, Parikh RY (2010) Biological synthesis of metallic nanoparticles. Nanomed Nanotechnol Biol Med 6:257-262

2. Sanguiñedo $P$, María Fratila R, Belén Estevez M, Martínez De La Fuente J, Grazú V, Alborés S, Biosynthesis E (2018) Iss. 2 of silver nanoparticles using fungi and their antibacterial activity. Nano Biomed Eng 10:165-173

3. Lü T, Qi D, Zhang D, Zhang C, Zhao H (2019) Correction to: onestep synthesis of versatile magnetic nanoparticles for efficiently removing emulsified oil droplets and cationic and anionic heavy metal ions from the aqueous environment. Environ Sci Pollut Res 26:23207

4. Gandhi AD, Murugan K, Umamahesh K, Babujanarthanam R, Kavitha P, Selvi A (2019) Lichen Parmelia sulcata mediated synthesis of gold nanoparticles: an eco-friendly tool against Anopheles stephensi and Aedes aegypti. Environ Sci Pollut Res 26:23886-23898

5. Nagarajan D, Venkatanarasimhan S (2019) Copper(II) oxide nanoparticles coated cellulose sponge-an effective heterogeneous catalyst for the reduction of toxic organic dyes. Environ Sci Pollut Res 26:22958-22970

6. Zaki SA, Eltarahony MM, Abd-El-Haleem DA (2019) Disinfection of water and wastewater by biosynthesized magnetite 
and zerovalent iron nanoparticles via NAP-NAR enzymes of Proteus mirabilis 10B. Environ Sci Pollut Res 26:23661-23678

7. Mazumder JA, Perwez M, Noori R, Sardar M (2019) Development of sustainable and reusable silver nanoparticle-coated glass for the treatment of contaminated water. Environ Sci Pollut Res 26:23070-23081

8. Venkatesan EP, Kandhasamy A, Sivalingam A, Kumar AS, Ramalingam K, Joshua PJT, Balasubramanian D (2019) Performance and emission reduction characteristics of cerium oxide nanoparticle-water emulsion biofuel in diesel engine with modified coated piston. Environ Sci Pollut Res 26:1-10

9. Abd El-Maksoud EM, Lebda MA, Hashem AE, Taha NM, Kamel MA (2019) Ginkgo biloba mitigates silver nanoparticlesinduced hepatotoxicity in Wistar rats via improvement of mitochondrial biogenesis and antioxidant status. Environ Sci Pollut Res 26:1-11

10. Bhowmik PN, Barman P, Ahmed MA (2019) Iron-polyphenol complex nanoparticles for removal of greenhouse gas emission from bitumen and formation of paraffins. Environ Sci Pollut Res 26:1-8

11. Bhainsa KC, D'Souza SF (2006) Extracellular biosynthesis of silver nanoparticles using the fungus Aspergillus fumigatus. Colloids Surf B Biointerfaces 47:160-164

12. Sharma D, Kanchi S, Bisetty K (2015) Biogenic synthesis of nanoparticles: a review. Arab J Chem. https://doi.org/10.1016/j.arabj c.2015.11.002

13. Kuppusamy P, Yusoff MM, Maniam GP, Govindan N (2016) Biosynthesis of metallic nanoparticles using plant derivatives and their new avenues in pharmacological applications: an updated report. Saudi Pharm J 24:473-484

14. Agarwal $\mathrm{H}$, Venkat Kumar S, Rajeshkumar S (2017) A review on green synthesis of zinc oxide nanoparticles: an eco-friendly approach. Resour Technol 3:406-413

15. Ahmed MS, Soundhararajan R, Akther T, Kashif M, Khan J, Waseem M, Srinivasan H (2019) Biogenic AgNPs synthesized via endophytic bacteria and its biological applications. Environ Sci Pollut Res 26:1-8

16. Molnár Z, Bódai V, Szakacs G, Erdélyi B, Fogarassy Z, Sáfrán G, Varga T, Kónya Z, Tóth-Szeles E, Szücs R, Lagzi I (2018) Green synthesis of gold nanoparticles by thermophilic filamentous fungi. Sci Rep 8:3943

17. Dhanaraj $S$, Bharathiraja $P$, Dhandapani R, Subbaiya R, Kathireshan AK (2018) Biosynthesis and characterization of silver nanoparticles from Aspergillus niger and its antibacterial activity. Res J Pharm Technol 11:5282-5286

18. Xue B, He D, Gao S, Wang D, Yokoyama K, Wang L (2016) Biosynthesis of silver nanoparticles by the fungus Arthroderma fulvum and its antifungal activity against genera of Candida, Aspergillus and Fusarium. Int J Nanomed 11:1899-1906

19. Paul NS, Yadav RP (2015) Biosynthesis of silver nanoparticles using plant seeds and their antimicrobial activity. Asian J Biomed Pharm Sci 5:26

20. Popli D, Anil V, Subramanyam AB, Rao SN, Rai RV, Govindappa M (2018) Endophyte fungi, Cladosporium species-mediated synthesis of silver nanoparticles possessing in vitro antioxidant, anti-diabetic and anti-Alzheimer activity. Artif Cells Nanomed Biotechnol 46:676-683

21. Saravanan M, Arokiyaraj S, Lakshmi T, Pugazhendhi A (2018) Synthesis of silver nanoparticles from Phenerochaete chrysosporium (MTCC-787) and their antibacterial activity against human pathogenic bacteria. Microb Pathog 117:68-72

22. Arisha AH, Ahmed MM, Kamel MA, Attia YA, Hussein MMA (2019) Morin ameliorates the testicular apoptosis, oxidative stress, and impact on blood-testis barrier induced by photo-extracellularly synthesized silver nanoparticles. Environ Sci Pollut Res 117:1-14
23. Barbosa AC, Silva LP, Ferraz CM, Tobias FL, de Araújo JV, Loureiro B, Braga GM, Veloso FB, de Freitas Soares FE, Fronza M, Braga FR (2019) Nematicidal activity of silver nanoparticles from the fungus Duddingtonia flagrans. Int J Nanomed 14:2341-2348

24. Neethu S, Midhun SJ, Radhakrishnan EK, Jyothis M (2018) Green synthesized silver nanoparticles by marine endophytic fungus Penicillium polonicum and its antibacterial efficacy against biofilm forming, multidrug-resistant Acinetobacter baumanii. Microb Pathog 116:263-272

25. Verma VC, Kharwar RN, Gange AC (2010) Biosynthesis of antimicrobial silver nanoparticles by the endophytic fungus Aspergillus clavatus. Nanomedicine 5:33-40

26. Amerasan D, Nataraj T, Murugan K, Panneerselvam C, Madhiyazhagan P, Nicoletti M, Benelli G (2016) Myco-synthesis of silver nanoparticles using Metarhizium anisopliae against the rural malaria vector Anopheles culicifacies Giles (Diptera: Culicidae). J Pest Sci 89:249-256

27. Soni N, Prakash S (2012) Efficacy of fungus mediated silver and gold nanoparticles against Aedes aegypti larvae. Parasitol Res 110:175-184

28. Banu AN, Balasubramanian C (2014) Myco-synthesis of silver nanoparticles using Beauveria bassiana against dengue vector, Aedes aegypti (Diptera: Culicidae). Parasitol Res 113:2869-2877

29. Prabakaran K, Ragavendran C, Natarajan D (2016) Mycosynthesis of silver nanoparticles from Beauveria bassiana and its larvicidal, antibacterial, and cytotoxic effect on human cervical cancer (HeLa) cells. RSC Adv 6:44972-44986

30. Gola D, Malik A, Namburath M, Ahammad SZ (2018) Removal of industrial dyes and heavy metals by Beauveria bassiana: FTIR, $\mathrm{SEM}, \mathrm{TEM}$ and AFM investigations with $\mathrm{Pb}$ (II). Environ Sci Pollut Res 25:20486-20496

31. Gola D, Dey P, Bhattacharya A, Mishra A, Malik A, Namburath $M$, Ahammad SZ (2016) Multiple heavy metal removal using an entomopathogenic fungi Beauveria bassiana. Bioresour Technol 218:388-396

32. Singh P, Kim YJ, Zhang D, Yang DC (2016) Biological synthesis of nanoparticles from plants and microorganisms. Trends Biotechnol 34:588-599

33. Pal S, Tak YK, Song JM (2015) Does the antibacterial activity of silver nanoparticles depend on the shape of the nanoparticle? A study of the gram-negative bacterium Escherichia coli. J Biol Chem 290:1712-1720

34. Van Dong P, Ha C, Binh L, Kasbohm J (2012) Chemical synthesis and antibacterial activity of novel-shaped silver nanoparticles. Int Nano Lett 2:9

35. Lu Z, Zhu H, Fu P, Wang Y, Zhang Z, Lin H, Liu P, Zhuang Y, Hong $\mathrm{K}$, Zhu W (2010) Cytotoxic polyphenols from the marine-derived fungus Penicillium expansum. J Nat Prod 73:911-914

36. Vivek R, Thangam R, Muthuchelian K, Gunasekaran P, Kaveri K, Kannan S (2012) Green biosynthesis of silver nanoparticles from Annona squamosa leaf extract and its in vitro cytotoxic effect on MCF-7 cells. Process Biochem 47:2405-2410

37. Ahluwalia V, Kumar J, Sisodia R, Shakil NA, Walia S (2014) Green synthesis of silver nanoparticles by Trichoderma harzianum and their bio-efficacy evaluation against Staphylococcus aureus and Klebsiella pneumonia. Ind Crops Prod 55:202-206

38. Prakasham RS, Kumar BS, Kumar YS, Shankar GG (2012) Characterization of silver nanoparticles synthesized by using marine isolate Streptomyces albidoflavus. J Microbiol Biotechnol 22:614-621

39. Chitra K, Annadurai G (2014) Antibacterial activity of pHdependent biosynthesized silver nanoparticles against clinical pathogen. Biomed Res Int 2014:725165

40. Kim SH, Lee HS, Ryu DS, Choi SJ, Lee DS (2011) Antibacterial activity of silver-nanoparticles against Staphylococcus aureus and Escherichia coli. Korean J Microbiol Biotechnol 39:77-85 
41. Chauhan N, Tyagi AK, Kumar P, Malik A (2016) Antibacterial potential of Jatropha curcas synthesized silver nanoparticles against food borne pathogens. Front Microbiol 7:1748

42. Salar RK, Sharma P, Kumar N (2015) Enhanced antibacterial activity of streptomycin against some human pathogens using green synthesized silver nanoparticles. Resour Technol 1:106-115

43. Panáček $A$, Smékalová $M$, Večeřová $R$, Bogdanová $K$, Röderová $M$, Koláŕ $M$, Kilianová $M$, Hradilová Š, Froning JP, Havrdová $M$, Prucek R, Zbořil R, Kvítek L (2016) Silver nanoparticles strongly enhance and restore bactericidal activity of inactive antibiotics against multiresistant Enterobacteriaceae. Colloids Surf B Biointerfaces 142:392-399

Publisher's Note Springer Nature remains neutral with regard to jurisdictional claims in published maps and institutional affiliations. 